\title{
Boa Postura: Uma Preocupação com a Estética, a Moral ou a Saúde?
}

Adriane Vieira*

Jorge Luiz de Souza**

\begin{abstract}
Resumo: A intenção neste estudo foi compreender, a partir de um olhar da Antropologia do corpo e da saúde, as motivações daqueles que procuram uma educação postural. Método: $\mathrm{A}$ análise das informações foi realizada a partir de 50 entrevistas semiestruturadas realizadas com participantes do programa de extensão "Escola Postural" da ESEF/UFRGS. Resultados: A análise das informações permitiu identificar o argumento principal para justificar o interesse em participar de um programa de educação postural: a vontade de ter boa postura. Conclusão: A importância dada à boa postura demonstrou uma interseção permanente entre saúde, estética e moral.
\end{abstract}

Palavras-chave: Postura. Antropologia.

\section{BOA POSTURA: UMA PREOCUPAÇÃO COM A ESTÉTICA, COM A MORAL OU COM A SAÚDE?}

A ênfase dada ao corpo no século XX fez proliferar inúmeras formas de intervenção que procuram de diferentes maneiras melhorar a aparência, o desempenho, a beleza, a saúde e o bem-estar. Ter uma aparência jovem e saudável, garantida pela imagem e pelo sentimento de um corpo forte, ágil, resistente e belo, é um valor incorporado na contemporaneidade e motivo para investimentos pessoais através de medidas preventivas, de exercícios e de tratamentos, como demonstram, por exemplo, os estudos antropológicos reunidos no livro $\mathrm{Nu} \&$ Vestido, que aborda a cultura do corpo carioca (GOLDENBERG, 2002).

\footnotetext{
* Fisioterapeuta e Doutora em Ciências do Movimento Humano pela Universidade Federal do Rio Grande do Sul, Porto Alegre, RS, Brasil. E-mail: adriane.vieira@gmail.com

** Professor do departamento de Educação Física da Escola de Educação Física da Universidade Federal do Rio Grande do Sul, Porto Alegre, RS, Brasil. E-mail: jlsouza@esef.ufrgs.br
} 
Essas providências voltadas ao embelezamento, à prevenção, à manutenção ou à recuperação da saúde exaltam o valor do corpo, acentuando-se de diferentes maneiras nos discursos a necessidade de cuidar da aparência externa e do bem-estar interno (SHUSTERMAN, 2000). Entretanto, numa cultura onde o corpo se tornou um produto de consumo, há uma tendência a estarmos mais atentos à aparência, pois, segundo Sabino (2002, p. 157):

[...] uma cultura na qual o entretenimento, o consumismo e a publicidade se tornam pilares existenciais, a espetacularização passa a constituir o cotidiano dos indivíduos preocupados com seu marketing pessoal. O corpo, além de representar a verdade desse indivíduo, é também sua vitrine.

A boa postura é um dos requisitos que ganha destaque quando o tema é a prevenção, a manutenção ou a recuperação da saúde e do bem-estar corporal. Os meios de comunicação (FIORAVANTI; SHIMMA, 1992; GLOCK, 1997) e os artigos científicos (CASAROTTO, 1995; SCHENK, 1996; VANDERTHOMMEN et al., 1999) divulgam que $80 \%$ da população é acometida, em algum momento da vida, por dores nas costas e ressaltam a necessidade de ter-se uma boa postura para garantir ou recuperar o bom funcionamento do organismo. Nos hospitais, escolas e clínicas surgem programas de educação da postura que, embasados em conhecimentos biomédicos, visam ensinar posturas corretas para tratar ou evitar problemas álgicos (CHUNG, 1996; SOUZA, 1996; HENROTIN et al., 2001). Entretanto, como bem demonstra Vigarello (1978) no livro Le Corps Redressé, os discursos sobre a boa postura são frequentemente permeados por ideais estéticos e morais do posicionamento do corpo, indicando, na maioria das vezes, uma preocupação primeira com a aparência corporal. Postura saudável e belo porte confundem-se nos discursos sobre a postura e tornam-se quase sinônimos: a forma e a ação corporal idealizadas como perfeitas são as referências principais para julgar a normalidade da postura e para indicar como proceder à manutenção ou à construção de uma postura saudável, acreditando-se que a construção do porte idealizado pode garantir o bem-estar do indivíduo.

Movimento, Porto Alegre, v. 15, n. 01, p. 145-165, janeiro/março de 2009. 
Nossa intenção, neste artigo, é compreender quais são as motivações daqueles que procuram, dentre tantas práticas corporais disponíveis e difundidas na atualidade, uma educação postural para cuidar de si mesmo.

\section{Metodologia}

Nosso interesse, neste artigo, foi desenvolver uma reflexão, a partir de um olhar da Antropologia do corpo e da saúde, sobre as motivações daqueles que procuram uma educação postural. Essas informações tinham por objetivo conhecer quais eram as concepções de postura, as motivações e as expectativas daqueles que procuram uma intervenção sobre a postura.

Para atingir esse objetivo, definimos uma metodologia que nos possibilitasse acessar o modo como a postura era concebida e percebida por aqueles que, interessados em uma educação da postura, inscreviam-se no Programa de Escola Postural da ESEF/UFRGS. Nesse processo traçamos escolhas e construímos um ponto de vista particular - um dentre tantos possíveis - sobre o universo de significados, experiências, motivos, sentimentos, aspirações, crenças e atitudes relacionadas à boa postura e à sua educação, na tentativa de contemplar um espaço mais profundo de relações, de processos e de fenômenos que não poderiam ser reduzidos à operacionalização de variáveis (MINAYO, 1993).

A primeira escolha foi definir a pesquisa como qualitativa. Segundo Bogdan e Biklen (1992), a pesquisa qualitativa é descritiva e sua preocupação essencial é o significado.

De acordo com Guba (1985) e Triviños (1987), uma vez que, na pesquisa qualitativa, os fenômenos são complexos e vinculados ao contexto, os dados subjetivos são considerados importantes fontes de informação. Por isso, esses autores privilegiam métodos qualitativos e um delineamento aberto, os quais se estruturam de acordo com os objetivos e com o referencial teórico-filosófico da pesquisa em questão.

Movimento, Porto Alegre, v. 15, n. 01, p. 145-165, janeiro/março de 2009. 
Assim, a análise das informações coletadas durante a pesquisa é entendida como um caminho de pensamento e de prática, desenvolvidos a partir do referencial teórico da antropologia do corpo e da saúde. Na antropologia, segundo Víctora, Knauth e Hassen (2000), reconhece-se que o mundo real só existe, de fato, na medida em que nos tornamos parte dele e que ele faz sentido para nós. As investigações são interpretações de microprocessos sociais, nos quais os indivíduos compartilham significados relativos ao universo social que coabitam. Segundo Geertz (1978, p. 31), o texto antropológico é uma interpretação no sentido de que é "algo construído", "algo modelado", onde a imaginação e a perspectiva do autor não podem ser negadas. A interpretação visa "salvar o 'dito' em um tal discurso da sua possibilidade de extinguir-se e fixá-lo em formas pesquisáveis".

Pelos objetivos apresentados, essas prerrogativas metodológicas nos pareceram adequadas e serviram de referência à análise das informações coletadas junto aos participantes desta pesquisa.

As análises apresentadas neste artigo e os depoimentos citados são decorrentes de entrevistas semiestruturadas realizadas com uma amostra intencional composta por 50 participantes (36 mulheres e 14 homens com idades entre 20 e 73 anos) inscritos no Programa de Extensão "Escola Postura da ESEF/UFRGS" nos anos de 2002 e 2003. A divulgação do Programa foi feita por cartazes afixados na ESEF/UFRGS e por notas nos jornais Zero Hora e Correio do Povo; o critério de inclusão na amostra foi estar inscrito no Programa, não havendo critério de exclusão. No primeiro semestre de 2002 as entrevistas foram realizadas com 11 participantes no transcorrer do Programa. No segundo semestre de 2002 foram realizadas na semana anterior ao seu início, com 19 participantes e, no primeiro semestre de 2003, com 20. As entrevistas duraram em média trinta minutos e foram realizadas em uma sala apropriada (com a presença apenas do pesquisador e do entrevistado), gravadas em fita cassete e transcritas na integra. Posteriormente, as unidades de significado foram agrupadas para compor os resultados e a discussão apresentada neste artigo.

As questões que nortearam a entrevista abordavam concepções de postura, percepções corporais, motivações e expectativas em relação a um programa de educação postural.

Movimento, Porto Alegre, v. 15, n. 01, p. 145-165, janeiro/março de 2009. 
Todos os nomes citados são fictícios. Os entrevistados foram informados que um estudo de doutorado estava sendo realizado durante o programa e todos permitiram que as informações coletadas fossem utilizadas, assinando um termo de consentimento.

As queixas e as motivações que levaram os entrevistados a procurar uma educação postural apresentaram muitas sutilezas que os particularizam, mas também permitiram identificar, em suas falas, um argumento principal para a participação num programa de educação da postura: a vontade de ter uma boa postura. Este norteou, portanto, as reflexões deste artigo.

\subsection{Resultados e discussão: UMA falHa No "CARTÃo de VISITAS"}

Uma das queixas frequentes entre os entrevistados foi a insatisfação com suas posturas: consideravam que não se mantinham suficientemente retos e simétricos, ou seja, que não correspondiam aos parâmetros de boa postura vigentes na nossa cultura. A coluna "fletida" e os "ombros caídos" foram os problemas mais citados em relação à forma corporal e foram associados a fatores hereditários, à maneira habitual de executar determinadas atividades, à idade e à falta de disciplina, de controle e de cuidado com a postura. Dentre os trinta e dois participantes da pesquisa que citaram a aparência corporal como uma forte motivação para procurar um programa de educação da postura, quatorze deles não apresentavam um quadro álgico relevante, sendo a preocupação com a boa postura relacionada a outros fatores. Um dos fatores que chama a atenção é o componente relacional dessa preocupação, a qual está normalmente vinculada à cobrança advinda de familiares, amigos ou colegas de serviço, como demonstra Antônio:

Quem tem má postura, muitas vezes não repara, né? mas algumas pessoas cobravam essa questão da postura [...] Eu até, não sei, não dou muita bola pra isso, até porque a gente não repara, mas as pessoas reparavam, e em função disso, né? (ANTÔNIO, 45 anos).

As palavras de Adriano, ao definir a postura, ajudam-nos a entender por que ter boa postura pode tornar-se uma preocupação relevante à vida social: "Postura [...] é a principal forma de manifestação

Movimento, Porto Alegre, v. 15, n. 01, p. 145-165, janeiro/março de 2009. 
do corpo, eu vejo assim, então digamos que ela seja basicamente o teu cartão de visitas" (ADRIANO, 32 anos).

Se pensarmos a postura como um cartão de visitas, ${ }^{1}$ entendemos por que os outros tendem a interferir na postura alheia. A postura torna-se quase um artigo, uma roupagem que, como tal, pode ser modificada e que demonstra o cuidado consigo e o status do indivíduo. O "cartão de visitas" de Antônio não correspondia ao modelo de boa postura, o que lhe trazia problemas, pois, segundo ele mesmo, exercendo um cargo político, sua aparência adquiria visibilidade e tendia a ser julgado pelos outros. Mas é interessante salientar que Antônio não tinha dores musculoesqueléticas. Sua "anormalidade" não gerava, diversamente do que sugere os discursos sobre a postura, uma queixa "interna" de dor: estava relacionada a uma queixa que vinha "de fora"; era o olhar do outro que, ao sentir-se incomodado, lhe indicava um problema e lhe solicitava uma mudança.

Na maioria das histórias dos participantes, a cobrança em relação à postura não teve início na vida adulta; pelo contrário, a cobrança começou na infância ou na adolescência, no seio da própria família, como descreve Cecília:

O pai sempre nos corrigiu a postura. Então esse negócio de andar muito corcunda, muito curvado pra frente e tal. Isso foi uma coisa que ele, desde criança, sempre procurou nos corrigir. E eu levei isso pela vida afora, né? Então como surgiu essa oportunidade, eu achei que era o momento de ver se as coisas estão corretas ou o que poderia melhorar (CECÍLIA, 59 anos).

Esses olhares que fiscalizam a postura corporal nos lembram muito os dizeres de Foucault (1987) sobre os corpos disciplinados e dóceis, sendo a família uma das instituições incumbidas de controlar e educar a postura. Em outro momento, Cecília complementou seu comentário, deixando claro como, no seu entender, essa intervenção sobre a postura foi exercida de forma positiva pelo seu pai:

${ }^{1}$ O termo cartão de visitas, referindo-se ao corpo, também aparece no texto de Malysse (2002, p. 80) quando fala de sua impressão sobre os corpos cariocas. A autora afirma: "cada um parece fazer tudo o que pode para que seu corpo esteja à altura de seu ego e se transforme em sua perfeita encarnação - como se exibisse seu cartão de visitas."

Movimento, Porto Alegre, v. 15, n. 01, p. 145-165, janeiro/março de 2009. 
O pai era muito carinhoso nesse ponto, ele era muito delicado, [...] ele chegava e dava um toquezinho de leve [...], dava um toquezinho com a mão, 'vamos endireitar o corpo', principalmente na hora das refeições. Hoje eu acho que isso não é certo, porque na hora da refeição tem de ser tranqüilo [...] Quando eu sentava, e ele pegava a mais curva, ele fazia sentar do lado dele na mesa pra ele poder só dar um toquezinho, e a gente sabia o que ele queria [...] era aqueles modos: que sentasse direitinho, comesse direitinho e tal, foi bem na fase que a gente tinha lá seus 10, 12 anos" (CECÍLIA, 59 anos).

Ao participar da entrevista, Cecília tinha 59 anos e, apesar da insistência de seu pai e de seu cuidado com a própria postura, não possuía, como Antônio, uma "coluna reta" e também não apresentava queixas de dor. Ela, como Antônio e outros, não chegavam a ter um desconforto "interno" que relacionasse à sua postura. Para esses participantes, o desconforto vem de uma informação "externa", de um comentário alheio ou da visibilidade da sua postura em um espelho ou em uma fotografia.

Helena foi outra participante aconselhada a endireitar-se por ser "torta", mas que considerava nunca ter tido problemas por causa de sua postura. Como os demais, eram os outros que lhe apresentaram um problema: "Quando eu era bem mais jovem, minha irmã mais velha vivia me cutucando: endireita as costas, tá com as costas tortas, e eu acho que eu tenho, minha postura não é muito boa, meio corcunda" (HELENA, 51 anos).

Helena inscreveu-se no programa por insistência de sua filha, que é professora de Educação Física e preocupa-se com a postura da mãe, mas Helena afirmou não se interessar muito em repensar a sua postura. É relevante salientar que outros participantes também vieram ao programa não por um interesse pessoal, mas pela insistência de outros.

Nos comentários dos participantes, foi possível perceber que as cobranças estão relacionadas à expectativa de ver o corpo reto, sendo as indicações mais corriqueiras: "fique reto", "sente-se direito" -indicações, conselhos ou cobranças que denotam uma ação corporal, sem

Movimento, Porto Alegre, v. 15, n. 01, p. 145-165, janeiro/março de 2009. 
deixar claro como fazer para se adquirir o comando solicitado. "Ah, sim, o dia inteiro dentro de casa, isso aí sempre, senta direito, isso aí sempre foi uma coisa que teve por natureza na minha infância dizer: 'senta direito', sabe?" (CÉSAR, 23 anos).

Essas considerações nos levam a questionar a idéia, presente em nossa cultura, de que, para melhorar a postura de alguém é suficiente solicitar-lhe que fique "direito", que "se endireite", que "fique reto", sem explicitar o que é e nem indicar como se faz "direito". Ao falar sobre “O que é boa postura?", Feldenkrais (1977, p. 92) aponta que a palavra direito "[...] não expressa o que queremos conseguir ou ver depois que o aperfeiçoamento tiver acontecido". Ademais, afirma que, muitas vezes, nem mesmo a pessoa que solicita à outra que sente ou fique "direito" sabe exatamente o que é necessário para se assumir tal postura. Podemos concordar com Feldenkrais (1977) que a idéia de "direito" é vaga e não apresenta nenhuma indicação explicita do que deve ser feito. Entretanto, considerando as colocações de Mauss (1974) sobre as técnicas corporais, podemos dizer que, se não existe, explicitamente, uma técnica que ensine a ficar reto ou direito - como existe, por exemplo, uma técnica que ensina a nadar - existe implicitamente um consenso cultural sobre o que é "ficar direito" e sobre como fazemos para conseguir isso. Trata-se de uma técnica que, na maioria das vezes, não é ensinada formalmente, mas que se aprende pela imitação, pelo tom de voz e pelo próprio sentido das palavras utilizadas para solicitar a postura correta.

Torna-se também relevante refletir nas acepções da palavra direito e, a partir disso, nos diferentes significados que podem acompanhar a solicitação "Senta direito!". A palavra direito explicita acepções físico-morais, mostrando a imbricação entre a atitude do corpo e as atitudes morais, uma atitude que é supervisionada pelo outro mediante uma indicação sempre mais subentendida que explícita tal qual o era no século XII (SCHMITT, 1995), ou mesmo no século XVII (VIGARELLO, 1978). Por séculos, vêm-se indicando uma norma social, uma exigência para os contornos corporais, sem se deixar claro os meios pelos quais essa norma pode ser alcançada com facilidade; na maioria das vezes, o próprio tom de voz que acompanha o comando "Senta direito!" indica implicitamente a rigidez

Movimento, Porto Alegre, v. 15, n. 01, p. 145-165, janeiro/março de 2009. 
que deve acompanhar o ato, tal qual em um comando militar, mantendo-se viva uma representação social bastante antiga de boa postura.

Postura e rigidez estão associadas não somente pela solicitação de erguer o tronco acionando os músculos das costas, mas pela própria maneira que é solicitada. A maneira de falar e as palavras têm sentidos múltiplos que influenciam a educação da postura. Indicam associações culturais entre estados do corpo e da alma, preceitos morais e ideais estéticos; e, assim como a palavra direito nos remete a muitas sutilezas, da mesma forma as acepções do verbo relaxar (o qual também tem conotações físico-morais) merece considerações quando tratamos do tema postura corporal. Segundo Ferreira (1999), dicionário Aurélio da língua portuguesa, relaxar refere-se a: [1] diminuir a força ou a tensão de; afrouxar; [2] dispensar do cumprimento de (lei ou dever); [3] corromper, perverter, depravar; [4] tornar-se negligente, desleixarse; [5] desmoralizar-se. Assim, os diferentes significados presentes nessas definições nos levam a associar o relaxamento, isto é, a diminuição da tensão muscular nas posturas do cotidiano, a valores simbólicos de fraqueza, de descumprimento dos deveres, de descuido consigo, de desmoralização e de perversão. Como afirma Antônio:

Quando eu tenho que apresentar algum trabalho... eu me preocupo pra ter uma postura mais correta. Porque... a questão da postura também parece ser uma questão de quanto tu é uma pessoa que cuida ou que é relaxada ou que não é relaxada com teu corpo, né? Veja bem, isso tem de ser uma coisa constante, não em determinados momentos, tinha que se preocupar sempre com isso, né? Mas, às vezes, eu me solto mesmo. Sou meio rebelde também, de repente é a minha rebeldia corporal. Bom, a coisa é mais complexa, de repente, do que uma simples questão postural, eu acho (ANTÔNIO, 45 anos).

Há, portanto, uma relação conflituosa entre boa postura e tensão/ relaxamento muscular. Apesar de muitos entrevistados considerarem que o conforto está relacionado ao relaxamento muscular, ao mesmo tempo consideram que a boa postura (o estar reto) é o oposto do relaxamento. Ao observar Antônio, podia-se notar que ele não possuía uma musculatura relaxada, seus músculos eram encurtados e tensos.

Movimento, Porto Alegre, v. 15, n. 01, p. 145-165, janeiro/março de 2009. 
Sua "rebeldia" estava possivelmente mais relacionada a um relaxamento das normas de retitude do que a um relaxamento muscular, questões que são normalmente confundidas por acreditar-se que a má postura, sendo um relaxamento moral, está vinculada, por analogia, ao relaxamento muscular. Como diz Samanta durante a entrevista ao ser indagada se costumava ter cuidados com a sua postura:

Cuidado? Às vezes. É como eu te falei, às vezes eu fico bem nem aí, fico totalmente torta, deixa eu sofrer um pouquinho, sabe? De acordo com o meu estado de espírito. Às vezes eu sou super, até me elogiam [...] Se tu fica direitinho, né, até as pessoas acham legal. E tu tem de servir de modelo, às vezes tu fica de modelo, até tu enrijece um pouco pra servir de modelo, né? Mas eu acho, quando tu vê que a correria é tanta, tu acaba, eu acabo não prestando atenção [...] Gera um conflito, tu tenta relaxar, mas ao mesmo tempo tu tem de manter (SAMANTA, 38 anos).

Samanta é professora de Educação Física e considera necessário "enrijecer um pouco" os músculos para servir de modelo a seus alunos, ${ }^{2}$ demonstrando como a idéia de um corpo tenso predomina nas concepções de boa postura. Segundo Goldenberg e Ramos (2002, p. 31), na hodierna cultura do corpo, a qual "classifica, hierarquiza e julga a partir da forma física, não basta não ser gordo(a) - é preciso construir um corpo firme, musculoso e tônico, livre de qualquer marca de relaxamento ou de moleza".

Também podemos considerar a fala de Taísa sobre a boa postura:

Ah, postura é uma forma mais adequada de fazer, por exemplo, eu tô, né, relaxada, fazer os movimentos de uma forma correta. Eu entendo postura fazer, né, porque muitas vezes a gente, o modo de andar, de levantar, né? Eu tenho consciência que eu tenho postura errada, por exemplo, no sentar, levantar (TAÍSA, 40 anos).

\footnotetext{
${ }^{2}$ Lupton (2003), ao falar do cidadão ideal que o currículo de Educação Física em Saúde impõe às escolas em vários estados australianos, também chama atenção para a preocupação dos professores de Educação Física em precisar corresponder aos ditames de um corpo ideal porque são postos, diante dos alunos, como modelos desse discurso.
}

Movimento, Porto Alegre, v. 15, n. 01, p. 145-165, janeiro/março de 2009. 
A boa postura é, então, normalmente pensada como incompatível com um estado de relaxamento muscular, que leva simbolicamente ao desleixo, à perda de uma atitude corporal moralmente adequada - em outras palavras, a uma perda da autodisciplina e do autocontrole. O indivíduo deve "fazer", ou seja, produzir no próprio corpo a postura correta, a qual é tida como necessária ao cumprimento das normas sociais da boa disciplina. Normas que, apesar de revestidas de um discurso salutar, parecem estar sempre permeadas por uma preocupação moral com a aparência do corpo (VIEIRA; SOUZA, 2002).

A relação entre força/fraqueza muscular e força/fraqueza moral é muito bem apresentada e discutida por Duarte (1986) ao traçar um olhar antropológico sobre a vida nervosa nas classes trabalhadoras. $\mathrm{O}$ autor utiliza a noção de perturbação físico-moral para pensar a representação social do fenômeno do nervoso, que também pode ser usada para pensar a representação dos desvios posturais. Nesse sentido, podemos inferir que a preocupação moral com o relaxamento muscular adscreve a postura termos como correção, controle e comando, pois continua sendo na atitude do corpo que o sujeito demonstra ser moralmente correto, disciplinado, controlado e direito. Tal preocupação desconsidera o fato de que "ser/estar torto" não significa necessariamente relaxamento ou fraqueza muscular e que "ser/estar reto" não implica tensão ou força muscular VIEIRA (2004); são associações corriqueiras - frequentemente distorcidas - da relação entre posicionamento corporal e estado de tensão muscular. Trata-se possivelmente do equívoco mais significativo e problemático na compreensão da postura corporal e que mais pode prejudicá-la.

Lapierre e Aucouturier (1985) nos faz pensar, a partir da perspectiva teórica da psicomotricidade, apresentam uma interpretação sobre a possível relação existente entre o estado de tensão dos nossos músculos e a forma que organizamos nossas ações, nossa afetividade e nossos relacionamentos:

A contração dinâmica voluntária é a maneira de agir no mundo e constitui, por isso, a referência inicial em torno da qual se organizam todas as condutas de ação. Por outro lado, a contração tônica é uma maneira

Movimento, Porto Alegre, v. 15, n. 01, p. 145-165, janeiro/março de 2009. 
de estar no mundo, de senti-lo. Ela constitui a base de referência sobre a qual a afetividade e a relação com os outros se organiza (LAPIERRE; AUCOUTURIER, 1985 , p. 23).

Se considerarmos verdadeira tal afirmação, podemos dizer que é possível introjetar, na carne, um ideal moral; atuando sobre a postura, a qual é mantida principalmente pela contração tônica dos músculos, estamos indicando à pessoa uma maneira de estar e de ressentir o mundo e interferindo na sua afetividade e na sua relação com o outro. O modo de educar a postura, as instruções e orientações sugeridas e as práticas propostas não atuam somente na mecânica corporal. As ações pedagógicas (formais ou informais) sempre interferem, de uma forma ou outra, na construção de corpos-sujeitos e na forma que eles devem agir no espaço e relacionar-se no âmbito social.

Os comandos que visam controlar o desalinhamento corporal - desalinhamento incômodo a quem vê sinal de desleixo nessa atitude alheia - muitas vezes não indicam o que deve ser feito para modificar a atitude; os meios que poderiam facilitar a organização corporal para permitir o sentar vertical não são considerados, ou são até mesmo desconhecidos. Ao ouvir, assimilar e internalizar essa voz de comando, o indivíduo passa a esforçar-se para endireitar a coluna através do enrijecimento dos músculos das costas e aprende a associar esforço muscular à boa postura e ao "bom comportamento".

Se pensarmos a postura como uma questão de aparência corporal, resultante de um equilíbrio/desequilíbrio muscular, podemos dizer que sua construção depende, principalmente, da autodisciplina ou do autocontrole, sendo cada indivíduo responsável (e culpado) por sua boa postura, assim como pela sua juventude, beleza e saúde e visão que, segundo Goldenberg e Ramos (2002), predominam na atualidade. Nesse sentido, a boa postura se apresenta como um sucesso pessoal, como uma virtude, um cartão de visitas, algo conquistável pela dedicação. Como afirma Vanessa:

Eu acho...eu sei que eu não tenho a boa postura, né? Mas eu acho que me falta disciplina, né? Ai, eu fico me perguntando o que é uma boa postura: tu ficar sempre retinha e caminhar em cima do salto? Talvez

Movimento, Porto Alegre, v. 15, n. 01, p. 145-165, janeiro/março de 2009. 
era isso que eu queria. Quer dizer em cima do salto, direitinho, mas por quanto tempo eu agüentaria?" (VANESSA, 45 anos).

Vanessa demonstra interesse em corresponder aos padrões estéticos da boa postura e da elegância feminina e considera que isso seria possível através do empenho pessoal e da autodisciplina, mas também reconhece que, para tanto, teria de ultrapassar seus limites de conforto e bem-estar corporal; ou seja, para corresponder ao modelo de perfeição, é provável que tenha que abrir mão de um estado de "conforto interno". Comentário que demonstra a possível contradição entre os discursos que defendem a postura correta como um prérequisito para o bem-estar corporal. Também é importante salientar a idéia presente nessa visão de que para ter boa postura basta ter disciplina e esforçar-se, sugerindo que, sem isso, não é possível ter uma postura - física ou moral - corretas.

Apesar da idéia e da valorização de um "controle interno" para a obtenção ou manutenção da boa postura terem predominado na fala dos entrevistados, elas não foram unânimes. Alguns participantes demonstraram acreditar que a boa postura depende de um "controle externo". Ilda e Cecília, por exemplo, apesar de, na infância, acharem chato o controle de seus familiares sobre suas posturas, hoje o valorizam por considerar que, sem esse controle exercido, suas posturas agora seriam piores. A relevância de um controle externo para a aquisição ou manutenção da boa postura foi também citada por Vanessa, a qual considera que sua má postura está associada à falta de um controle externo na infância e na adolescência: "Sempre achei que a minha postura é muito feia. Eu acho até que foi uma falha na infância, na adolescência, ou na escola, ninguém me cobrou a postura, né?".

Vanessa parece acreditar, assim como Ilda e Cecília, que, se tivesse sido cobrada na infância, hoje teria uma postura melhor. E Vanessa considera, assim como Amanda e Eduarda, que só vai melhorar se alguém exercer sobre ela essa cobrança "externa". Para essas participantes, a mudança é vista como dependente do interesse e do controle do outro, não delas mesmas. A responsabilidade pelo descumprimento das normas é deslocada do sujeito para o grupo social.

Movimento, Porto Alegre, v. 15, n. 01, p. 145-165, janeiro/março de 2009. 
A inclusão do outro na responsabilização pela boa ou pela má postura levam-nos a considerar as diferentes concepções leigas sobre as causas dos problemas de saúde apresentadas por Helman (2003). Segundo o autor, todos os indivíduos apresentam um modelo explicativo com consistência e lógica interna sobre as causas de seus problemas. Esse modelo pode estar embasado em conhecimentos científicos e/ ou em crenças culturais e folclóricas que normalmente fazem parte de concepções mais abrangentes sobre as origens dos infortúnios em geral. $\mathrm{O}$ autor divide as causas como residindo: dentro do indivíduo, no mundo natural, no mundo social e no mundo sobrenatural.

Em relação à postura, foi possível identificar que alguns participantes consideraram que a causa da suas más posturas advinha de uma vulnerabilidade pessoal decorrente, por exemplo, de um fator hereditário - de algo que está localizado dentro do corpo, mas fora de controle pessoal e que, portanto, não depende de ações individuais e sociais. Todavia, pelos relatos apresentados acima, podemos perceber que a maioria dos entrevistados parece oscilar entre considerar a causa de suas más posturas uma questão de descuido individual e/ ou social. O controle sobre a postura e os cuidados com ela são identificados pelos participantes como uma norma social a ser cobrada e obedecida a fim de manter a boa imagem de si e do grupo ao qual se pertence. A boa/má postura pode ser vista como uma preocupação com a degenerescência pessoal e coletiva (VIGARELLO, 1978), o que justifica uma preocupação com a postura não somente na situação atual, mas também no futuro.

Alguns entrevistados evidenciaram a preocupação com o definhamento da aparência, sendo a imagem do velhinho que perde sua exuberância física o emblema desses temores presentes entre os participantes e do interesse em cuidar da postura:

Eu vejo que, se eu não fizer algo, a evolução vai ser pra como a gente vê os velhinhos caminhando na rua, encurvadinhos, de bengala, dando passos tremidos, e, claro, isso é uma coisa que ninguém quer pra si (RONALDO, 38 anos).

Eu tô muito curvada [...] eu me olho de perfil, e aqui a gente vê [...] E eu não quero ficar daquelas velhas,

Movimento, Porto Alegre, v. 15, n. 01, p. 145-165, janeiro/março de 2009. 
sabe como é, toda curvadinha, né, eu não quero. E...eu pensei 'não, eu vou me arrumar, né, arrumar a coluna que tá muito largada, porque até pra botar roupa fica melhor, né? (JÚLIA, 68 anos).

Mas o interesse pela educação da postura também demonstrou ser uma preocupação em favor dos outros, principalmente filhos e netos. Soraia, por exemplo, procurou o programa porque, apesar de considerar que tinha boa postura, sentia dores e queria adquirir mais informações sobre a postura para resolver essas dores e para ajudar os filhos a evitar problemas futuros:

Eu acho importante na pessoa, eu acho que é uma das coisas que te deixa mais bonito, mais saudável, com ar saudável, né? A pessoa retinha, não empinada, que eu também acho que é muito artificial, mas eu acho super triste ver um jovem, que falam tanto que os adolescentes têm os ombros pra frente, caidinhos, tudo. É uma coisa que eu corrijo muito nos meus filhos, que eu acho assim que depois vai causar um problema, eles vão ser um adulto pra toda a vida com aquele problema, então já corrijo antes. Boa postura, pensei, pelo menos que era o corpo um pouco, o mais reto possível, né? Não sei, eu acho que quem tem boa postura não sente dores nas costas (SORAIA, 42 anos).

A fala acima, assim como a de outros participantes, demonstra que o interesse em aprender sobre a postura não é apenas daqueles que querem corrigir-se, mas daqueles que querem corrigir os outros, mais uma vez demonstrando a presença de um controle social sobre a postura corporal. Também nos remete à dúvida sobre até que ponto conotações estéticas estão subjacentes a um discurso que - mediante o argumento de que, se não se fizer algo para melhorar o desalinhamento, um dia esse "desleixo" será a causa de dores e patologias - defende a necessidade de alinhamento corporal. Soraia é um exemplo que convida-nos a refletir: ela faz uma relação entre alinhamento corporal e dor, considerando importante corrigir a postura dos filhos a fim de evitar-lhes problemas de coluna e outros mais; mas ela mesma é uma pessoa que, apesar de considerar-se bem alinhada, tem queixa de dores.

Movimento, Porto Alegre, v. 15, n. 01, p. 145-165, janeiro/março de 2009. 


\begin{abstract}
A gente sempre teve a impressão de que as dores começariam mais perto dos 60 anos, né? E, quando a gente chegou aos 40 , a gente não se sente que tá velha, e eu já comecei com dores bem ruins aos 40 anos. Então eu me assustei com isso, aí eu disse 'ah não, quem sabe conhecendo mais alguma coisa que eu tô fazendo errado, pra corrigir, né? (SORAIA, 42 anos).
\end{abstract}

O caso de Soraia sugere que o alinhamento corporal talvez não seja garantia de bem-estar corporal e que outras questões devem ser pensadas e consideradas para que se encontre esse bem-estar, pois, mesmo correspondendo ao padrão de boa postura, Soraia se queixa de dores que não consegue entender e resolver.

Outro argumento, que nos remete a uma reflexão, foi apresentado por Ronaldo, que utilizou para justificar a necessidade de corrigirse os corpos perfeitos dos livros de anatomia. Ao comparar-se com as imagens dos livros Ronaldo afirma:

Nos livros de anatomia [...] eu não vejo o modelo dos homenzinhos curvadinhos. Então claro que eu tenho algo de diferente do padrão desejado. Então, apesar de isso não me gerar dor ainda, se eu não fizer algo pra corrigir, a evolução natural é que isso passe a ser fonte do dor [...]. Então algo deve ser feito. Nesses últimos tempos é que eu comecei a perceber mais isso e também eu comecei a estudar mais ortopedia. Aí a coisa se tornou mais evidente pra mim (RONALDO, 38 anos).

Devemos considerar que essas imagens de corpos perfeitos não aparecem apenas nos livros de anatomia, mas em todos os materiais publicitários que utilizam corpos humanos. As imperfeições nos contornos corporais são visualizadas somente em sujeitos comuns, estando, de certa forma, banidas do mundo cultural, o que em muito contribui para a construção simbólica de que corpos normais e saudáveis são corpos retos. ${ }^{3}$

\footnotetext{
${ }^{3}$ Sabino (2002) também chama a atenção para isso afirmando que, "através do avanço tecnológico e da expansão das telecomunicações, a imagem da perfeição corpórea passa a habitar, de forma constante, o cotidiano. A 'imperfeição' física dos indivíduos comuns defronta-se, a cada instante, com imagens de 'corpos perfeitos' em telas de cinema, TVs, computadores e outdoors. Tais imagens [...] tendem a induzir à perseguição desse tipo ideal de corpo sob a égide da felicidade". (p.144-5)
}

Movimento, Porto Alegre, v. 15, n. 01, p. 145-165, janeiro/março de 2009. 
A relação, presente nos livros e na fala dos participantes, entre má postura - considerada como desalinhamento corporal - e dor não foi evidente em muitos dos próprios entrevistados, dentre os quais uns se queixavam de má postura, mas sem apresentar dores, enquanto outros se queixavam de dores, mas sem apresentar má postura. Bruske, Souza e Vieira (2003) também não identificaram correlação entre o desalinhamento da cabeça em relação ao tronco e a dor na região cervical ao fazer uma análise estatística com base em fotografias e questionários de dor obtidos dos participantes da Escola Postural daESEF/UFRGS entre 1998 e 2003. Talvez estejam certos os defensores das biotipologias: eles afirmaram, na década de 50, que nada comprova que a má postura inevitavelmente gera mal-estar corporal ou patologias no sistema musculoesquelético (VIGARELLO, 1978; RASCH; BURKE, 1977; SHELDON, 1950). Mesmo porque, como afirmam Kendall, McCreary e Provance (1995), defensores da necessidade de alinhamento corporal, dificilmente encontramos alguém que corresponda à postura ideal. Portanto, considerando que quase todas as pessoas apresentam "desvios", facilmente encontramos uma alteração na estrutura musculoesquelética que possa justificar uma queixa de dor. As causas das dores musculoesqueléticas parecem envolver muitos outros fatores e são muito mais complexas do que o exposto na maioria das teorias que as relacionam à postura corporal, como bem demonstram os comentários dos participantes. No entanto, não encontramos nos artigos publicados sobre postura, discussões a respeito de fatores culturais que envolvem a educação postural, sugerindo a necessidade de uma reflexão mais ampla sobre essa temática entre os profissionais da área da saúde.

\section{ConsideraçõES FinAIS}

A imagem do corpo em perfeito alinhamento, constante na história ocidental, continua sendo forte referência quando se fala de postura, termo que inclusive subentende quase sempre um julgamento. Falar de postura é como que dizê-la (ou pensá-la) boa ou má, reta ou torta, direita ou desviante - em um sentido no qual parece estar imbricada uma avaliação do caráter daquele que a possui. Quando alguém pensa

Movimento, Porto Alegre, v. 15, n. 01, p. 145-165, janeiro/março de 2009. 
sobre a postura, é a imagem do corpo idealizado na nossa cultura equilibrado, belo, retilíneo - que se lhe afigura; esse senso comum, ilustrado pelas falas dos entrevistados, legitima-se e fundamenta-se nas perspectivas teóricas e nas abordagens pedagógicas e terapêuticas.

Por mais que, nas últimas décadas, a postura tenha sido pensada em termos de mecânica corporal, argumentando-se que o cuidado com a postura é necessário para evitar as dores nas costas, ou seja, para manter ou recuperar a saúde e o bem-estar corporal, encontramos na fala dos entrevistados uma preocupação com a postura predominantemente estética e moral.

Temos de pensar se realmente a falta da perfeita retitude pode ser compreendida como um indício da má saúde. Se os próprios especialistas admitem que o organismo pode prescindir do perfeito alinhamento corporal, por que dar tanta ênfase a esse parâmetro na abordagem da postura corporal? Vale lembrar que estamos falando de pequenos desvios, e não de grandes alterações na estrutura corporal. A retitude, da qual muitos se reportam, é delimitada pela linha do fio de prumo em vez de sê-lo por uma imagem de verticalidade.

É coerente o argumento de que dores e patologias estão relacionadas a certas dificuldades posturais passíveis de serem tratadas; mas isso não significa que as dificuldades possam ser medidas pelo desalinhamento ou que se restrinjam a ele. Há muitos fatores intervenientes no funcionamento do sistema musculoesquelético e na forma de abordá-los que deveriam ser considerados.

O conhecimento e o controle sobre a postura são instrumentos de poder úteis tanto para disciplinar os corpos, impondo normas e regras, como para libertá-los, expondo-lhes suas possibilidades e fazendo-os refletir nas normas e regras vigentes. Devemos, então, estar atentos à forma que esses conhecimentos são apresentados e utilizados nas definições de boa postura. Temos de pensar nos sentidos que estão sendo constituídos, reproduzidos e incorporados nos discursos sobre a postura e nas propostas pedagógicas que visam facilitar o bem-estar corporal através de uma educação postural, pois os conhecimentos não se restringem à transmissão de parâmetros mecânicos sobre o corpo

Movimento, Porto Alegre, v. 15, n. 01, p. 145-165, janeiro/março de 2009. 
humano - eles estabelecem valores e englobam uma determinada maneira de compreender-se no mundo e de pensar a existência.

Good Body Posture: an esthetic, moral or health concern?

Abstract: This study was to comprehend, from a

Body and Health Anthropological point of view, the motivations from those who search a postural education program. Method: Fifty semi-structured interviews were analyzed. Results: One main argument was identify to justify their interest in joining a postural education program: the desire to have a good posture. Conclusion: The emphasis given to a good body posture shows a permanent intersection between health, esthetic and moral.

Keywords: Posture. Anthropology.

Buena postura: una preocupación con la estética, la moral o la salud?

Resumen: Nuestra intención en este estudio fue comprender, a partir de una mirada hacia la Antropología del cuerpo y de la salud, las motivaciones de aquellos que buscan una educación postural. Método: El con participantes del programa de extensión "Escuela Postural" de la ESEF/UFRGS. análisis de las informaciones se ha hecho a partir de 50 entrevistas semiestructuradas realizadas Resultados: El análisis de las informaciones ha permitido identificar un argumento principal para justificar el interés en participar de un programa de educación postural: el deseo de tener una buena postura. Conclusión: La importancia atribuida a la buena postura ha demostrado una intersección permanente entre salud, estética y moral.

Palabras-clave: Postura. Antropología.

\section{REFERÊNCIAS}

BOGDAN, R.C.; BIKLEN, S.K. Qualitative Research for Education: an Introduction to Theory and Methods. 2nd.ed. Boston: Allyn and Bacon, 1992.

BRUSCHI, P.J.; SOUZA J.L.; VIEIRA, A. Relação da Postura Ortostática da Coluna Cervical com a Dor. In: SALÃO DE INICIAÇÃO CIENTÍFICA, 15, 2003, Porto Alegre. Anais.... Porto Alegre: UFRGS, 2003. v. 1, n. 1, p. 561.

Movimento, Porto Alegre, v. 15, n. 01, p. 145-165, janeiro/março de 2009. 
CASAROTTO, R.A.; MURAKAMI, S.C. Grupo de Coluna e Back School. Revista de Fisioterapia da Universidade de São Paulo, São Paulo, v. 2, n. 2, p. 65-71, 1995.

CHUNG, T.M. Escola da Postura: Experiência do Hospital das Clínicas da Universidade de São Paulo. Acta Fisiátrica, São Paulo, v. 3, n. 2, p. 13-17, 1996.

DUARTE, L.F.D. Da Vida Nervosa nas Classes Trabalhadoras Urbanas. Rio de Janeiro: Graal, 1986.

FELDENKRAIS, M. Consciência pelo Movimento. São Paulo: Summus, 1977.

FERREIRA, A.B.H. Novo Aurélio Século XXI: o Dicionário da Língua Portuguesa. 3. ed. Rio de Janeiro: Nova Fronteira, 1999.

FIORAVANTI, C.; SHIMMA, E. O eixo frágil da humanidade: a coluna. Globo Ciência, São Paulo, set. 1992.

FOUCAULT, M. Vigiar e Punir: história da violência nas prisões. 14. ed. Petrópolis: Vozes, 1987.

GEERTZ, C. A Interpretação das culturas. Rio de Janeiro: Zahar, 1978.

GLOCK, C. É Preciso cuidar da coluna. Zero Hora, Porto Alegre, 30 ago. 1997. Caderno Vida, p. 8.

GOLDENBERG, M. (Org.). Nu e Vestido: dez antropólogos revelam a cultura do corpo carioca. Rio de Janeiro: Record, 2002.

GOLDENBERG, M.; RAMOS, M.S. A civilização das formas: o corpo como valor. In: GOLDENBERG, M. (Org.). Nu e Vestido: dez antropólogos revelam a cultura do corpo carioca. Rio de Janeiro: Record, 2002. p. 19-40.

GUBA, E.G. Criterios de Credibilidad en la Investigación Naturalista. In: SACRISTAN, J. G.; GOMEZ, A..P.(Ed.). La Enseñanza: su teoria y su práctica. Madrid: Grefol, 1985.

HELMAN, C. Cultura, Saúde e Doença. 4.ed. Porto Alegre: Artes Médicas, 2003.

HENROTIN, Y. et al. Définicion, Critères de Qualité et Evaluation d'un Programme de Type École du Dos. Rev. Rhum, Paris, v. 68, p. 185-191, 2001.

KENDALL, F.P.; MCCREARY, E.K.; PROVANCE, P.G. Músculos, Provas e Funções. 4. ed. São Paulo: Manole, 1995.

LAPIERRE, A.; AUCOUTURIER, B. Os Contrastes e a Descoberta das Noções Fundamentais. 2. ed. São Paulo: Manole, 1985.

LUPTON, D. Desenvolvendo-me por Inteiro: Cidadania, Neoliberalismo e Saúde contemporânea no Currículo de Educação Física. Movimento, Porto Alegre, v. 9, n. 3, p. 11-31, 2003.

MALYSSE, S. Em Busca dos (H)alters-Ego: Olhares Franceses nos Bastidores da Corpolatria Carioca. In: GOLDENBERG, M. (Org.). Nu e Vestido: dez antropólogos revelam a cultura do corpo carioca. Rio de Janeiro: Record, 2002. p. 79-137.

Movimento, Porto Alegre, v. 15, n. 01, p. 145-165, janeiro/março de 2009. 
MAUSS, M. Sociologia e Antropologia. São Paulo: Editora da Universidade de São Paulo, 1974.

MINAYO, M.C.S. (Org.). Pesquisa Social: teoria, método e criatividade. Petrópolis: Vozes, 1993.

RASCH, P.J; BURKE, R.K. Cinesiologia e Anatonia Aplicada: a ciência do movimento humano. 5. ed. Rio de Janeiro: Guanabara Koogan, 1977.

SABINO, C. Anabolizantes: Drogas de Apolo. In: GOLDENBERG, M. (Org.). Nu e Vestido: dez antropólogos revelam a cultura do corpo carioca. Rio de Janeiro: Record, 2002. p. 139-188.

SCHENK, R.J.; DORAN, R.L.; STACHURA, J.J.Learning. Effects of a Back Education Program. Spine, Philadelphia, v. 21, n. 19, p. 213-218, 1996.

SCHMITT, J.C. A moral dos Gestos. In: Sant'Anna, D.B. (Org.). Políticas do Corpo. São Paulo: Estação Liberdade, 1995. p. 21-38.

SHELDON, W.H. Les Varietes de la Constitution Physique de I'Homme. Paris: Presses Universitaire de France, 1950.

SHUSTERMAN, R. Performing Live: Aesthetic Alternatives for the Ends of Art. New York: Cornell University, 2000.

SOUZA, J.L. Efeitos de uma Escola Postural para Indivíduos com Dores nas Costas. Movimento, Porto Alegre, v. 5, p. 56-71, 1996.

TRIVIÑOS, A.N.S. Introdução à Pesquisa em Ciências Sociais: a Pesquisa Qualitativa em Educação. São Paulo: Atlas, 1987.

VANDERTHOMMEN, M. et al. Le Comportement Gestuel du Patient Lombalgique Fréquentant une École du Dos: Analyse Préliminaire d'un Test d'Évaluation. Ann. Réadaptation Méd. Phys., Paris, v. 42, p. 485-492, 1999.

VÍCTORA, C.G; KNAUTH, D.R.; HASSEN, M.N.A. Pesquisa Qualitativa em Saúde: uma introdução ao tema. Porto Alegre, Tomo, 2000.

VIEIRA, A. A Escola Postural sob a Perspectiva da Educação Somática: a Reformulação de um Programa de Extensão na ESEF/UFRGS. Dissertação (Mestrado) - Escola de Educação Física, Universidade Federal do Rio Grande do Sul. Porto Alegre, 2004.

VIEIRA, A.; SOUZA, J.L. A Moralidade Implícita no Ideal de Verticalidade da Postura Corporal. Revista Brasileira de Ciências do Esporte, Campinas, v. 23, n. 3, p.133-148, 2002.

VIGARELLO, G. Le Corps Redressé: Histoire d'un Pouvoir Pédagogique. Paris: Jean-Pierre Delarge, 1978.

Agradecimentos a CAPES

Recebido em: 29/04/2008

Aprovado em: 24/11/2008

Movimento, Porto Alegre, v. 15, n. 01, p. 145-165, janeiro/março de 2009. 